\title{
No posterior mandibular displacement in Angle Class II, division 2 malocclusion as revealed with electromyography
} and sirognathography

\author{
Urs Thüer, Bengt Ingervall, Walter Bürgin, and Arthur Demisch \\ Orthodontic Clinic, University of Bern, Switzerland
}

SUMMARY The activity of the anterior and posterior temporal, and of the masseter muscles was studied by electromyography and the position of the mandible by sirognathography. The recordings were made in 22 children, aged 8-13 years, with Angle Class II, division 2 malocclusion before and during treatment of their malocclusion. The treatment comprised two phases: proclination of the upper incisors and bite raising with a removable plate, and the subsequent correction of the distal occlusion with an activator. The aim of the study was to reveal signs of anterior mandibular positioning during the treatment.

The electromyographic recordings were made in the rest position of the mandible, and during maximal biting, chewing, and swallowing. The sirognathographic recordings comprised the positions of the mandible at rest, at intercuspation, and during tooth contact during chewing and maximal mandibular movements.

The muscle activity at rest was unchanged during the period of observation. The activity during maximal biting, chewing, and swallowing decreased during the phase of proclination, which was interpreted as a result of occlusal instability. The positions of the mandible at rest, at intercuspation, and during chewing were stable during the treatment. Neither the electromyographic recordings nor the recordings of mandibular positions revealed any signs of anterior mandibular positioning during the treatment of the Class II, division 2 malocclusion.

\section{Introduction}

The question of a possible posterior mandibular displacement in Angle Class II, division 2 malocclusion is controversial. The morphological character of this type of malocclusion (retroclination of the upper incisors in combination with a deep bite) invites such an assumption. Swann (1954) stated that one-third of cases with this malocclusion have a posteriorly displaced mandible in the intercuspal position. Based on cephalometric findings during orthodontic treatment, Erickson and Hunter (1985) concluded that in about one-quarter of their sample the mandible may have repositioned anteriorly during the treatment. On the other hand, Gianelly et al. (1989) found no difference in the position of the mandibular condyles between Class II malocclusion cases with steep incisors and a deep bite, and Class II cases without these characteristics. There was, therefore, no evidence that the steep upper incisors, in combina- tion with the deep bite, had forced the mandible backwards on closure into the intercuspal position.

Subjects with Angle Class II, division 2 malocclusion have been found to have a larger distance between the retruded and intercuspal mandibular positions than individuals with normal occlusion (Ingervall, 1968). This is at variance with the theory of a posterior mandibular displacement. If the mandible was posteriorly displaced in the intercuspal position, a further large retrusion would be unlikely.

In a previous nvestigation (Demisch et al., 1992), we made longitudinal recordings of the relationship between the retruded and intercuspal mandibular positions in children with Class II, division 2 malocclusion during their orthodontic treatment. The results corroborated the earlier findings by Ingervall (1968) of a large distance between the two mandibular positions before the start of the treatment. The develop- 
ment of the distance between the two mandibular positions during the treatment presented no evidence of an anterior mandibular repositioning when the upper incisors were proclined or during the subsequent treatment of the distal occlusion with an activator.

In the sample studied, the activity of the temporal and masseter muscles was also recorded with electromyography, and positions and movements of the mandible with sirognathography. Such recordings have previously been made during the treatment of children with Angle Class II, division 1 malocclusion with an activator in order to reveal a possible forward mandibular positioning induced by the activator treatment (Ingervall and Bitsanis, 1986; Thüer et al., 1989; Ingervall and Thüer, 1991). No signs of an anterior mandibular positioning during the treatment of Class II, division 1 malocclusion were found.

The present study reports the results of the application of these methods of investigation in the treatment of children with Class II, division 2 malocclusion. A change in the muscle activity in the rest position of the mandible or during biting, chewing, and swallowing during the treatment could be indicative of mandibular repositioning. The same would be true if sirognathographic recordings revealed a change in the rest position of the mandible or in the position of tooth contact during chewing, as well as of mandibular border movements during the course of the treatment.

\section{Subjects and methods}

The study included the same 22 children (11 boys and 11 girls) that took part in the previous investigation (Demisch et al., 1992). Their age varied between 8 years, 2 months and 12 years, 8 months (median age 10 years, 2 months). The children were selected from among those enrolling for treatment at the Orthodontic Clinic, University of Bern. They had an Angle Class II, division 2 malocclusion and fulfilled the following criteria: a bilateral distal occlusion with retroclined upper incisors and a large overbite, and no symptoms or signs of mandibular dysfunction.

The treatment protocol as well as the results of the treatment are described in detail in the previous report (Demisch et al., 1992). Briefly, the treatment comprised three phases. In the first phase, the upper incisors were proclined and the deep bite was corrected with an upper removable plate. In the second phase, the distal occlusion was corrected with an activator according to Herren (Herren, 1980; Demisch, 1984). The third phase was a phase of retention, which was accomplished with a retention activator. All 22 children completed the first phase of the treatment. The treatment was then discontinued in one child because of lack of cooperation.

\section{Electromyography (EMG)}

The activity of the right anterior and posterior temporal muscles, the right masseter muscle, and the left posterior temporal muscle was recorded with a DISA electromyograph with direct $(15 \mathrm{C} 04)$ and mean voltage $(31 \mathrm{Cl} 7)$ channels. The lower and upper frequency filters were set at 20 and $1000 \mathrm{~Hz}$, respectively. The EMG signals were displayed on an electrostatic writer (Gould ES 1000). Bipolar hook electrodes (Ahlgren, 1967) were used. The placement of the electrodes was as described earlier (Ingervall and Thilander, 1974; Ingervall and EgermarkEriksson, 1979).

Recordings were made in the rest position of the mandible (calibration $50 \mu \mathrm{V} /$ division, paper speed $5 \mathrm{~cm} / \mathrm{sec}$ ), during maximal bite in the intercuspal position (calibration $200 \mu \mathrm{V} /$ division, paper speed $5 \mathrm{~cm} / \mathrm{sec}$ ), and during chewing and swallowing of apple and peanuts (calibration $200 \mu \mathrm{V} /$ division paper speed $10 \mathrm{~cm} / \mathrm{sec}$ ).

The sequence of the recordings was as follows:

(1) in the rest position of the mandible;

(2) during chewing and swallowing of apple;

(3) during chewing and swallowing of peanuts;

(4) during maximal bite in the intercuspal position;

(5) a new recording in the rest position.

For the chewing tests, the child was given a standard piece of apple or three peanuts, and asked to chew and swallow in the habitual way.

Electromyographic recordings were made on two occasions (median time 27 and 22 days) before the start of the treatment. The next electromyographic recording was made at the end of phase one of the treatment, i.e. after proclination of the upper incisors and correction of the deep bite (median time 207 days after the start of the treatment). A fourth and fifth 
electromyographic recording was made 3 and 12 months, respectively, after the start of the activator treatment, which was initiated immediately on completion of phase one of the treatment.

\section{Analysis of the EMG recordings}

The muscle activity in the rest position was determined by measuring the mean voltage amplitude when the muscle activity was minimal during at least 5 seconds. For determination of the muscle activity during maximal bite, the mean voltage amplitude of the characteristic activity was measured.

The following measurements were made of the muscle activity during chewing (mean of six randomly selected chewing cycles during the act of chewing):

(1) maximal mean voltage amplitude and duration of the activity during the closing phase of the chewing cycle;

(2) characteristic mean voltage amplitude during the opening phase of the chewing cycle and duration of the opening phase.

The muscle activity during swallowing was analysed by measurement of the maximal mean voltage amplitude and duration of activity. In the further analyses, the activity in the right and left posterior temporal muscles, as well as the two recordings of the rest position activity were averaged.

\section{Recording of mandibular positions and movements}

The positions and movements of the mandible were recorded with a Sirognathograph (Siemens AG, Bensheim, Germany), which registered the location of a magnet fastened at the labial fold inferior to the lower central incisors. The magnet was incorporated in a custom-made acrylic holder glued to the labial surfaces of the teeth (Fig. 1). The position of the holder was individualized so as not to interfere with the occlusion or disturb mandibular movements. For each subject, the same holder was used throughout the period of investigation.

With the Sirognathograph, changes in position of the magnetic field are recorded by means of an antenna system attached to the head with a face-bow (Fig. 2). The antennae convert the changing magnetic field into electrical signals that are fed into a computing unit. The signals

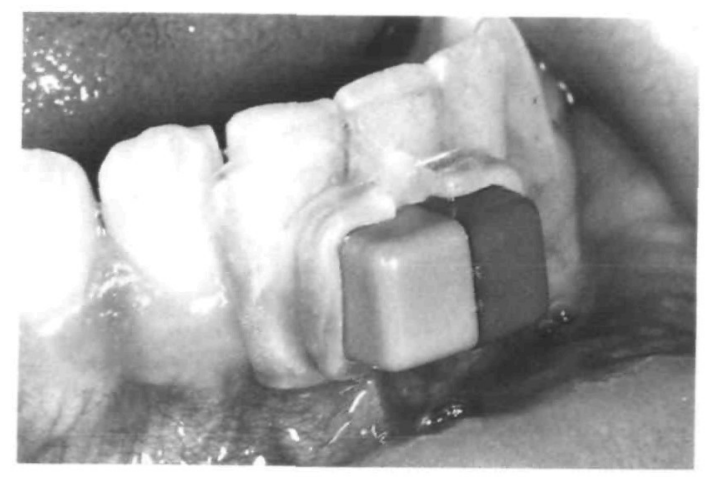

Figure 1 Magnet on lower incisors for sirognathographic recording.

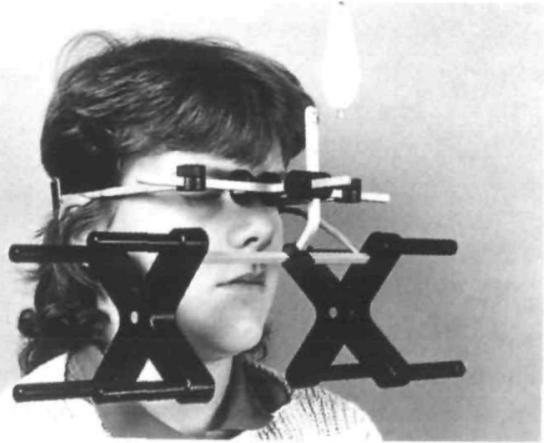

Figure 2 Subject with antennae for sirognathographic recording.

are processed into analog voltages representing movement in three planes as the axes of a threedimensional co-ordinate system.

The positions and movements of the magnet were simultaneously recorded in the sagittal and frontal planes with the aid of two $x / y$ plotters. Simultaneously, the analog signal from the Sirognathograph was digitized and stored in a computer for subsequent analyses. During the recordings, the subject sat upright with his or her head in natural balance without the use of a headrest. To help keep the head at rest during the recordings, a plumb-line bob was hung from the ceiling in front of the subject. The weight helped an observer to check the head position.

During the period of observation, major changes in the position of the teeth and in the intermaxillary relationship were accomplished by the treatment. Two different reference systems were therefore used. Before the start of the treatment and during the phase of proclin- 
ation of the upper incisors, the positions and movements of the magnet at the lower incisors were referred to a magnet placed in the deepest part of the palate (procedure I). This magnet was incorporated in an acrylic plate that fitted the upper jaw and was unchanged during the first phase of the treatment. At the start of each recording session, the acrylic plate was placed in the mouth and the signals from the magnet on the plate were recorded in the computing unit as the zero point for the subsequent recordings from the magnet in the lower jaw. After this calibration, the magnet in the upper jaw was removed and replaced by the magnet in the lower jaw. The locations of the magnet in the lower jaw thus always refer to the location of the magnet in the upper jaw, which was stationary during the period of observation.

During the phase of activator treatment the edge-to-edge position of the upper and lower central incisors was used as a reference position for the determination of the location of the mandible in the other positions and movements (procedure II). Each recording session when procedure II was used (phase of activator treatment) commenced with the recording of the position of the magnet at the lower incisors when the mandible was in the edge-to-edge position. This procedure was identical with a previously described method (Thüer et al., 1989).

\section{Recordings and measurements with procedure I}

In procedure I, after the establishment of the reference point, the following recordings were made in the order given:

(1) mandibular position in intercuspation;

(2) mandibular position at rest;

(3) movements and positions of the mandible during chewing of apple;

(4) new recordings of the mandibular position at rest.

The recordings displayed on the $x / y$ plotters were used as visual control while the actual measurements were made with a cursor on the graphic display of the computer. The positions of the mandible in intercuspation and during tooth contact while chewing were measured as $x$ and $y$ co-ordinates in relation to the zero point of the reference system (Fig. 3). Each chewing cycle during the act of chewing (until swallowing) was analysed. Those with a closing distance within $0.1 \mathrm{~mm}$ of the minimal value (indicating tooth contact) were chosen, measured, and averaged. The position of the mandible in the rest position ( $x$ and $y$ co-ordinates) was measured in relation to the mandibular position in intercuspation.

Recordings were made in 20 children on two occasions (median time 27 and 22 days) before the start of the treatment, and thereafter 3 months after the start of the treatment and at the end of the phase of proclination of the incisors. The deep bite and the position of the upper incisors made the placement of the magnet at the lower incisors impossible in two cases. The results of the two recordings made before treatment as well as of the two recordings made in the rest position at each recording session were averaged.

Recordings and measurements with procedure II

The recordings and measurements with procedure II were the same as in an earlier study (Thüer et al., 1989), where the method has been described in detail.

The following recordings were made at the start of the treatment with an activator and after 3 and 12 months of activator treatment:

(1) mandibular position in incisor edge-to-edge protrusion and the movement from this into the intercuspal position;

(2) maximal movements of the mandible (opening, laterotrusion, protrusion);

(3) mandibular position at rest and the movement from the rest position into the intercuspal position;

(4) movements and positions of the mandible during chewing of apple;

(5) new recording of the mandibular position at rest.

All measurements in the sagittal and frontal planes were made on the graphic display of the computer. In principle, the measurements included the determination of the overjet and the overbite, the size of the maximal movements of the mandible, the free-way space, and the anteroposterior position of the mandible in the rest position, the point of tooth contact in the anteroposterior direction during chewing, any transverse deviation of the mandible during maximal opening or in the rest position. The same rules as for procedure I for the measurement of 


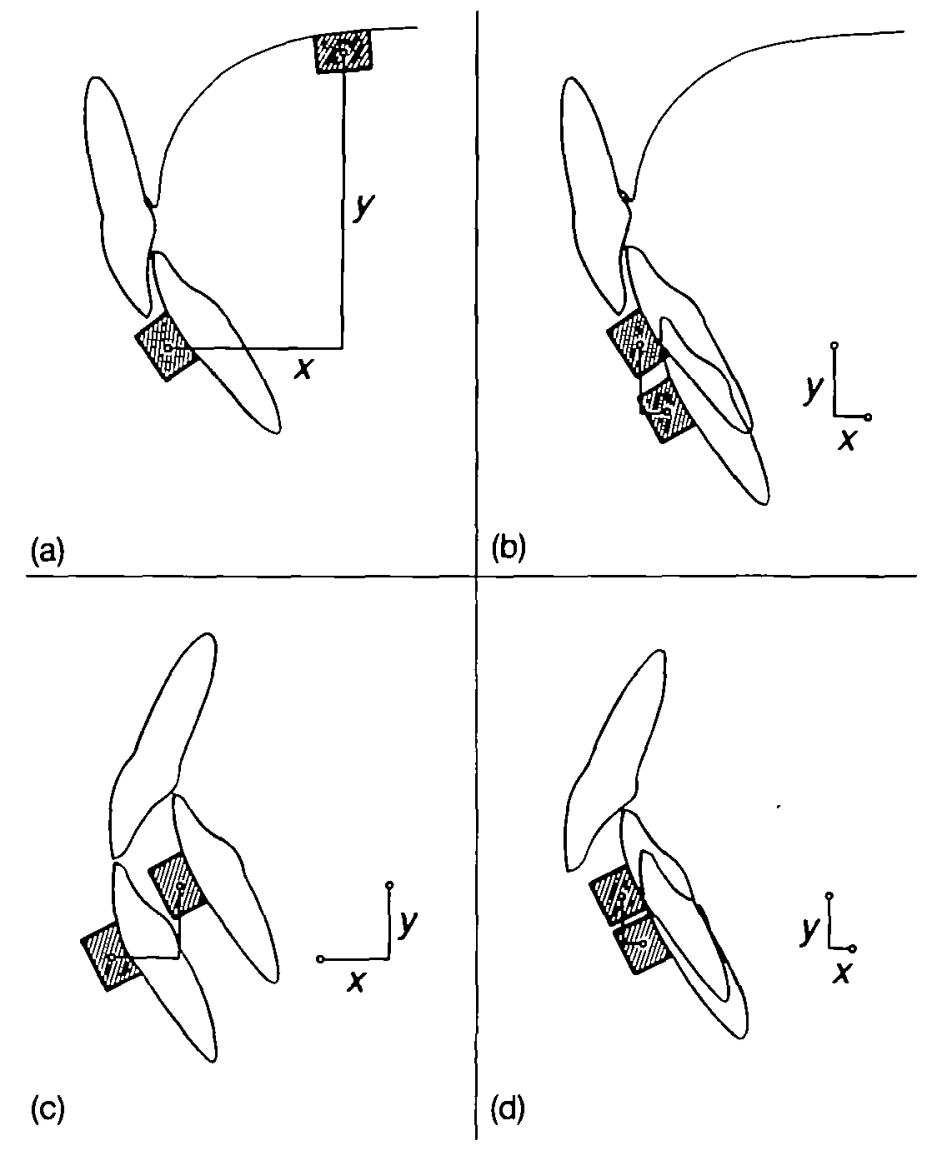

Figure 3 (a) $x$ and $y$-co-ordinates for determination of the mandibular position at intercuspation with procedure $I$. (b) and (d) Magnitude of freeway space ( $y$ ) and distance between intercuspal and anteropostenor position of the mandible in the rest position $(x)$ as measured with procedures I and II, respectively. (c) Distance between edge-to-edge and intercuspal mandibular positions in horizontal $(x)$ and vertical $(y)$ planes recorded with procedure II.

the chewing cycles and the averaging (chewing and rest position recordings) were applied.

Recordings during activator treatment were made in 15 children at the start of this phase of treatment and, thereafter, at 3 and 12 months.

\section{Statistical methods}

Accidental errors of the method (si) were calculated with the formula

$$
s i=\sqrt{\frac{\sum d^{2}}{2 n}}
$$

where $d$ is the difference between repeated observations.

Differences between recordings on consecutive occasions were tested with Wilcoxon's matched-pairs signed-ranks test.

\section{Results}

\section{Electromyography}

The two electromyographic recordings made before treatment were tested for systematic differences with Wilcoxon's matched-pairs signed-ranks test. Only two variables (the amplitude of the masseter muscle in the opening phase during the chewing of apple and the amplitude of the anterior temporal muscle during the chewing of peanuts) differed significantly between the two recordings. No other significant differences were found. The results of the two recordings made before the start of the treatment were, therefore, averaged for the further analyses.

The results of a subsequent electromyographic recording were tested for significant differences from the results of the previous 
recording (consecutive recordings) with Wilcoxon's matched-pairs signed-ranks test. No significant differences were found for the muscle activity in the rest position of the mandible or in the amplitude during the opening phase of the chewing cycle.

Significant differences between subsequent recordings during the first phase of the treatment were found for the amplitude during maximal bite and during the closing phase of the chewing cycle as well as during swallowing (Table ${ }^{1}$ ). In addition the activity in the posterior temporal muscle during maximal bite increased (median difference $66 \mu \mathrm{V}$ ) from 3 to 12 months after the start of treatment phase 2.

There were no significant differences between consecutive recordings in the duration of the closing or opening phases during chewing of apple and only one during chewing of peanuts. Thus, the duration of the closing phase in the posterior temporal muscle increased from a median value of $355 \mathrm{msec}$ at 3 months to $375 \mathrm{msec}$ at 12 months after the start of the activator treatment.

There were no significant changes with time in the duration of the activity during swallowing of peanuts, but during the swallowing of apple the duration increased in the anterior temporal muscle from a median value of $530 \mathrm{msec}$ to $695 \mathrm{msec}$, and in the masseter muscle from $440 \mathrm{msec}$ to $545 \mathrm{msec}$ from 3 to 12 months after the start of the activator treatment (phase two of treatment).

Table 1 Median and amplitude (in $\mu \mathrm{V}$ ) and range for the muscle activity in the rest position during maximal bite and during the closing phase of the chewing cycle as well as during swallowing.

\begin{tabular}{|c|c|c|c|c|c|c|c|c|}
\hline & \multicolumn{2}{|c|}{ Before treatment } & \multicolumn{2}{|c|}{ After proclination } & \multicolumn{2}{|c|}{$\begin{array}{l}\text { After } 3 \text { months } \\
\text { of activator } \\
\text { treatment }\end{array}$} & \multicolumn{2}{|c|}{$\begin{array}{l}\text { After } 12 \text { months } \\
\text { of activators } \\
\text { treatment }\end{array}$} \\
\hline & Median & $\begin{array}{l}\text { Range } \\
(=22)\end{array}$ & Median & $\begin{array}{c}\text { Range } \\
n=22)\end{array}$ & Median & $\begin{array}{l}\text { Range } \\
i=21)\end{array}$ & Median & $\begin{array}{l}\text { Range } \\
=21)\end{array}$ \\
\hline \multicolumn{9}{|l|}{ Rest position } \\
\hline Ant.temporal m. & 2.4 & $0-7.1$ & 2 & $0-10.8$ & 2 & $0-8.8$ & 2.7 & $0-8.1$ \\
\hline Post.temporal m. & 11 & $4.1-21.6$ & 6.8 & $1.4-32.4$ & 6 & $1.4-14.9$ & 7.1 & $1.4-39.2$ \\
\hline Masseter $\mathrm{m}$. & 0.3 & $0-5.7$ & 0.7 & $0-8.1$ & 1.4 & $0-8.1$ & 1.4 & $0-5.4$ \\
\hline \multicolumn{9}{|l|}{ Maximal bite } \\
\hline Ant.temporal m. & 427 & $61-742$ & $188^{* * *}$ & $88-577$ & 186 & $27-666$ & 212 & $88-585$ \\
\hline Post.temporal m. & 360 & $144-667$ & $202^{* * *}$ & $44-449$ & 234 & $41-447$ & $235^{*}$ & $111-588$ \\
\hline Masseter $\mathrm{m}$ & 181 & $33-486$ & 88 & $9-525$ & 88 & $11-433$ & 144 & $5-570$ \\
\hline \multicolumn{9}{|l|}{ Chewing of apple } \\
\hline Ant.temporal m. & 322 & $170-684$ & 270 & $122-435$ & 235 & $114-750$ & 202 & $98-826$ \\
\hline Post.temporal m. & 278 & $121-543$ & $214^{*}$ & $105-450$ & 239 & $124-517$ & 273 & $113-597$ \\
\hline Masseter $\mathrm{m}$. & 183 & $49-530$ & 147 & $51-370$ & 108 & 8-375 & 130 & $41-470$ \\
\hline \multicolumn{9}{|l|}{ Chewing of peanuts } \\
\hline Ant.temporal m. & 377 & $206-751$ & $307^{*}$ & $98-624$ & 292 & $61-1027$ & 230 & $133-933$ \\
\hline Post.temporal m. & 330 & $162-644$ & $270^{* * *}$ & $153-447$ & 542 & $156-666$ & 291 & $149-502$ \\
\hline Masseter m. & 229 & $90-548$ & 182 & $48-411$ & 124 & $19-668$ & 172 & $44-788$ \\
\hline \multirow{2}{*}{\multicolumn{9}{|c|}{ Swallowing of apple }} \\
\hline & & & & & & & & \\
\hline Ant.temporal m. & 244 & $97-438$ & $138^{* *}$ & $33-422$ & 166 & $11-244$ & 127 & $44-844$ \\
\hline Post.temporal m. & 213 & $104-474$ & $174^{*}$ & $38-438$ & 177 & $33-294$ & 208 & $77-433$ \\
\hline Masseter $\mathrm{m}$. & 99 & $22-533$ & 55 & $22-288$ & 44 & $0-411$ & 61 & $0-433$ \\
\hline \multicolumn{9}{|c|}{ Swallowing of peanuts } \\
\hline Ant.temporal m. & 244 & $77-877$ & $170^{* *}$ & $22-522$ & 149 & $44-655$ & 155 & $44-822$ \\
\hline Post.temporal m. & 263 & $111-524$ & $166^{* *}$ & $61-388$ & 194 & $66-422$ & 266 & $66-388$ \\
\hline Masseter m. & 149 & $0-399$ & 66 & $22-330$ & 30 & $0-466$ & 44 & $0-411$ \\
\hline
\end{tabular}

* $0.01<P<0.05 ; * 0.001<P<0.01, * * P<0.001$; indicates significant difference from previous recording. 


\section{Positions and movements of the mandible}

Only one variable (the vertical position of the point of tooth contact during chewing) recorded with sirognathographic procedure I differed significantly between the two recordings made before the start of the treatment. The accidental errors of the method in the determination of the anteroposterior and vertical positions of the mandible at intercuspation were 1.38 and $1.40 \mathrm{~mm}$, respectively. The corresponding values for the position of tooth contact during chewing were 1.55 and $1.12 \mathrm{~mm}$, and for the rest position 0.77 and $1.35 \mathrm{~mm}$.

No significant differences were found when consecutive recordings made before the start of the treatment and during the phase of proclination of the upper incisors were tested with Wilcoxon's matched-pairs signed-ranks test (Table 2). Thus, the intercuspal position of the mandible, like the position of tooth contact during chewing and the rest position remained stationary during the phase of proclination of the incisors. There was a numerical, though not significant, increase in the vertical position at intercuspation during the period of treatment. This is an effect of the bite-raising that was achieved with the orthodontic appliance during this phase of the treatment. The free-way space remained constant, however. On average, the mandible in the rest position was positioned posterior of the intercuspal position. In only one individual was the mandible at rest situated anterior to the intercuspal position before the start of the proclination. After 3 and 12 months of proclination, four and seven subjects, respectively, had a mandibular rest position anterior of the intercuspal position.

The size of the border movements of the mandible (maximal opening, protrusion, and lateral movements) did not change significantly during the phase of activator treatment as revealed by the sirognathographic recordings of procedure II. The same was true for the position of the mandible in the frontal plane during maximal opening and at rest. The distance between the edge-to-edge position of the mandible and the intercuspal position, i.e. the overjet, decreased from the start of the activator treatment to the second observation and from the second to the third recording session (Table 3 ). This is the improvement of the overjet brought about by the activator treatment. The overbite, like the position of the mandible at rest, and at tooth contact during chewing, remained constant during the period of observation (Table 3 ). At the start of the activator treatment seven subjects had a rest position anterior to the intercuspal position. This proportion remained constant, with eight and seven subjects, respectively, at the recordings at 3 and 12 months after the start of the activator treatment.

Table 2 Median position and range (in $\mathrm{mm}$ ) of the mandible at intercuspation and during tooth contact during chewing. The table also shows the position of the mandible at rest relative to the intercuspal position.

\begin{tabular}{|c|c|c|c|c|c|c|}
\hline & \multicolumn{2}{|c|}{ Before treatment } & \multicolumn{2}{|c|}{$\begin{array}{l}\text { After } 3 \\
\text { months of proclination }\end{array}$} & \multicolumn{2}{|c|}{ After proclination } \\
\hline & \multicolumn{2}{|c|}{$(n=20)$} & \multicolumn{2}{|c|}{$(n=20)$} & Median & $\begin{array}{l}\text { Range } \\
0)\end{array}$ \\
\hline $\begin{array}{l}\text { Position at intercuspation } \\
\text { relative to the zero point } \\
\text { of the co-ordinate system }\end{array}$ & & & & & & \\
\hline $\begin{array}{l}\text { Anteroposterior } \\
\text { Vertical }\end{array}$ & $\begin{array}{r}-14.5 \\
12.9\end{array}$ & $\begin{array}{c}-19.9--5.3 \\
6.9-18.7\end{array}$ & $\begin{array}{r}-14.6 \\
14.0\end{array}$ & $\begin{array}{r}-22.0--8.1 \\
5.6-18.8\end{array}$ & $\begin{array}{r}-15.0 \\
14.0\end{array}$ & $\begin{array}{c}-22.0-10.0 \\
9.4-21.4\end{array}$ \\
\hline \multicolumn{7}{|l|}{$\begin{array}{l}\text { Difference between the tooth } \\
\text { contact during chewing and } \\
\text { the intercuspal position }\end{array}$} \\
\hline $\begin{array}{l}\text { Anteroposterior } \\
\text { Vertical }\end{array}$ & $\begin{array}{r}0.1 \\
-0.4\end{array}$ & $\begin{array}{l}-1.5-1.4 \\
-2.9-1.4\end{array}$ & $\begin{array}{r}0.6 \\
-0.6\end{array}$ & $\begin{array}{l}-2.7-7.1 \\
-5.0-1.8\end{array}$ & $\begin{array}{r}0.6 \\
-0.5\end{array}$ & $\begin{array}{l}-5.2-3.3 \\
-3.9-2.0\end{array}$ \\
\hline \multicolumn{7}{|c|}{$\begin{array}{l}\text { Difference between intercuspal } \\
\text { and rest positions }\end{array}$} \\
\hline $\begin{array}{l}\text { Anteroposterior } \\
\text { Vertical (freeway space) }\end{array}$ & $\begin{array}{l}1.7 \\
4.5\end{array}$ & $\begin{array}{c}-0.3-4.2 \\
2.4-6.7\end{array}$ & $\begin{array}{l}1.3 \\
4.1\end{array}$ & $\begin{array}{r}-2.1-4.4 \\
2.2-6.4\end{array}$ & $\begin{array}{l}1.2 \\
4.4\end{array}$ & $\begin{array}{r}-6.1-5.8 \\
1.6-7.3\end{array}$ \\
\hline
\end{tabular}


Table 3 Median position (in $\mathrm{mm}$ ) and range, of the mandible at intercuspation and the position of the mandible at rest and at tooth contact during chewing in relation to the intercuspal position.

\begin{tabular}{|c|c|c|c|c|c|c|}
\hline & \multicolumn{2}{|c|}{ Start of activator treatment } & \multicolumn{2}{|c|}{$\begin{array}{l}\text { After } 3 \text { months of activator } \\
\text { treatment }\end{array}$} & \multicolumn{2}{|c|}{$\begin{array}{l}\text { After } 12 \text { months of activator } \\
\text { treatment }\end{array}$} \\
\hline & Median & $\begin{array}{l}\text { Range } \\
\text { 15) }\end{array}$ & Median & $\begin{array}{l}\text { Range } \\
\text { 15) }\end{array}$ & Median & Range \\
\hline \multicolumn{7}{|l|}{$\begin{array}{l}\text { Position at intercuspation } \\
\text { relative to the zero point } \\
\text { of the co-ordinate system }\end{array}$} \\
\hline Anteroposterior & 5.5 & $2.3-8.1$ & $2.6 * *$ & $1.3-4.9$ & $1.6^{* *}$ & $0.7-3.3$ \\
\hline Vertical & 3.7 & $1.6-5.8$ & 3.2 & $1.6-7.0$ & 3.3 & $1.1-5.0$ \\
\hline \multicolumn{7}{|c|}{$\begin{array}{l}\text { Difference between intercuspal } \\
\text { and rest position }\end{array}$} \\
\hline Anteroposterior & 1.0 & $-3.7-5.1$ & -0.3 & $-3.3-3.4$ & 1.0 & $-1.2-3.3$ \\
\hline Vertical & 4.5 & $1.8-10.1$ & 4.9 & $2.7-6.6$ & 4.4 & $2.0-6.1$ \\
\hline \multicolumn{7}{|c|}{$\begin{array}{l}\text { Difference between intercuspal } \\
\text { position and position of tooth } \\
\text { contact on chewing }\end{array}$} \\
\hline Anteroposterior & 0.4 & $-0.6-2.0$ & 0.1 & $-4.9-1.5$ & 0.2 & $-1.0-2.2$ \\
\hline Vertical (freeway space) & 0.2 & $-2.3-1.3$ & 0.0 & $-1.4-1.2$ & 0.2 & $-0.5-1.9$ \\
\hline
\end{tabular}

** $0.001<P<0.01$; indicates significant difference from previous recording.

Relationship between the retruded and intercuspal mandibular positions, and electromyographic and sirognathographic variables

In the subjects studied, the relationship between the retruded (RCP) and intercuspal (ICP) mandibular positions was recorded with a gnathothesiometer. The results of these recordings have been reported previously (Demisch et al., 1992). The anteroposterior difference between the two positions was found to decrease from the start of the treatment until the end of the activator treatment and to increase again somewhat during the phase of retention after the treatment.

In order to evaluate whether the anteroposterior difference between RCP and ICP, and the change in this distance during the period of observation were related to results of the electromyographic and sirognathographic recordings, rank correlation coefficients of Spearman were calculated. The variables examined were the anteroposterior distance between RCP and ICP, the activity of the temporal and masseter muscles in the rest position, and the anteroposterior position of the mandible at intercuspation, in the rest position and during tooth contact while chewing. Coefficients of correlation were calculated between the variables mentioned as recorded before treatment, after proclination of the upper incisors, at the start of the activator treatment and after 12 months of activator treatment as well as between the changes in these variables between the occasions mentioned.

There were no significant correlations between the anteroposterior RCP-ICP distance and the other variables before or after the proclination of the upper incisors. Nor were there any significant coefficients of correlation for the changes of these variables during phase I of the treatment. There was also no significant correlation between the muscle activity and the mandibular positions recorded with sirognathography.

After 12 months of activator treatment, there was a correlation (rho $=0.59,0.01<P<0.05$ ) between the position of the mandible at intercuspation and the RCP-ICP distance. This means that cases with a large overjet tended to have a large RCP-ICP difference.

\section{Analysis of individual cases}

The same variables that were studied in the correlation analyses were used to follow the development of individual cases during the phase of proclination of the upper incisors.

The sirognathographic recordings from the start and at the end of the phase of proclination revealed a statistically significant $(0.01<P<$ 
0.05 ) anterior positioning of the mandible at intercuspation in six subjects. Three of these children also chewed in a more anterior position at the end of the phase of proclination, but three still used their old, more posterior mandibular position. It may be assumed that the three children who still used their original mandibular position for chewing occupied a slightly protruded convenience position at closure to intercuspation from the rest position. In fact, one of these children had the greatest anterior repositioning of the mandible at rest.

Of the three children who both positioned their mandible more anteriorly at intercuspation and also chewed in a more anterior position one had a very large $(>4 \mathrm{~mm})$ distance between RCP and ICP. It may be assumed, therefore, that the anterior positioning of the mandible at intercuspation and chewing in this child also represents an anterior convenience position. The remaining two children had small $\mathrm{RCP}-\mathrm{ICP}$ distances both before and at the end of the phase of proclination. In these two children, therefore, the more anterior position of the mandible at intercuspation and chewing at the end of phase I of the treatment is unlikely to be a convenience protrusion, and may indicate a true mandibular repositioning after proclination of the upper incisors.

\section{Discussion}

During the period of observation no significant difference was found in the muscle activity in the rest position of the mandible for any of the muscles studied. The results are, therefore, in line with previous findings during the recording of the muscle activity during the treatment of Angle Class II, division 1 malocclusion with an activator (Ingervall and Thüer, 1991). This result suggests that the rest position of the mandible remained stable both during the phase of proclination of the upper incisors and during the following phase of correction of the distal occlusion with an activator. The recordings of the muscle activity in the rest position, therefore, gave no evidence of an anterior repositioning of the mandible during any of the phases of treatment.

During the phase of proclination of the upper incisors, there was a simultaneous bite raising accomplished by the removable acrylic plate with its anterior bite plane. During this phase of the treatment, the activity of the anterior and poster- ior temporal muscles decreased during maximal bite, during chewing and swallowing. This is probably a result of occlusal instability induced by the bite raising and wearing of the appliance. A stable occlusion has been shown to be a prerequisite for maximal muscle activity during biting (Ingervall and Egermark-Eriksson, 1979; Ingervall et al., 1979; Bakke and Möller, 1980) and an improvement in the occlusion has been shown to result in an increase of the maximal mean voltage amplitude during chewing (Ingervall and Egermark-Eriksson, 1979; Ingervall et al., 1979; Bakke et al., 1982; Ingervall and Carlsson, 1982; Möller et al., 1984). The opposite effect was shown to result from the introduction of an experimental interfering occlusal contact (Riise and Sheikholeslam, 1984).

The duration of the muscle activity during swallowing of apple increased during the activator treatment. This is probably also a consequence of occlusal instability. Similar effects on the amplitude during biting, chewing and swallowing were found in the previous study of the muscle activity during treatment of Angle Class II, division 1 malocclusion (Ingervall and Bitsanis, 1986). The activity during maximal biting was also studied in children with Class II, division 1 malocclusion being treated with an activator or with headgear as well as during treatment of children with Class I malocclusion (Ingervall and Thüer, 1991). A decrease in the activity during the course of the treatment was also found in these groups. In both studies mentioned the decrease was also taken to be an effect of occlusal instability.

There was, on average, no significant change in the position of the mandible during the phase of proclination of the upper incisors either at intercuspation or in the rest position or during chewing. The sirognathographic recording, therefore, did not reveal any signs of anterior repositioning of the mandible during this phase of the treatment for the group. The analysis of individual cases showed, however, that a repositioning of the mandible may sometimes have taken place as exceptions from the general trend.

The results of the sirognathographic recordings during the phase of activator treatment largely agreed with those of the previous study of children with Class II, division I malocclusion (Thüer et al., 1989), i.e. a successive reduction of the overjet with an unchanged overbite, as well as a stable anteroposterior position at 
rest and unchanged position during chewing in relation to the intercuspal position. In neither of the two investigations was there a decrease in the range of maximal protrusion of the mandible during the activator treatment. It has been recommended that the range of maximal protrusion be measured during the treatment and has been claimed that a reduction is indicative of an anterior mandibular repositioning (Petit and Chateau, 1984). In summary, neither the sirognathographic recordings during the phase of proclination nor those during activator treatment revealed any signs of anterior mandibular positioning except possibly in isolated individuals.

The correlation analysis of the present study did not reveal any relation between the RCPICP distance and the muscle activity at rest or with the sirognathographic variables during phase I of the treatment. The results of the functional recordings, therefore, do not favour the interpretation of a large RCP-ICP distance as a sign of persistent anterior mandibular positioning at intercuspation. It is more likely that the large RCP-ICP distance recorded in a few subjects at the end of the phase of proclination and bite raising (Demisch et al., 1992) is explicable as a convenience protrusion of the mandible at intercuspal wax bite recording in these individuals.

A relationship between the anteroposterior RCP-ICP distance and the overjet was found at the recording 12 months after the start of the activator treatment. This is probably an effect of less advanced progress of the treatment with remaining excessive overjet in some children (12 children still in the active phase of activator treatment).

\section{Address for correspondence}

Dr Urs Thüer

Klinik für Kieferorthopädie

Freiburgstrasse 7

CH-3010 Bern

Switzerland

\section{References}

Ahlgren J 1967 An intercutaneous needle electrode for kinesiologic EMG studies. Acta Odontologica Scandinavica 25: 15-19

Bakke M, Möller E 1980 Distortion of maximal elevator activity by unilateral premature tooth contact. Scandinavian Journal of Dental Research 80: 67-75
Bakke M, Möller E, Thorsen N M 1982 Occlusal control of temporalis and masseter activity during mastication (Abstr). Journal of Dental Research 81: 257

Demisch A 1984 Herren's dentofacial orthopedics. In: Graber T M, Neumann B (eds) Removable orthodontic appliances, 2nd edn. Saunders, Philadelphia, pp. 310-331

Demisch A, Ingervall B, Thüer U 1992 Mandibular displacement in Angle Class 1I, div. 2 malocclusion. American Journal of Orthodontics and Dentofacial Orthopedics (in press)

Erickson L P, Hunter W S 1985 Class II, division 2 treatment and mandibular growth. Angle Orthodontist 55: 215-224

Gianelly A A, Petras J C, Boffa J 1989 Condylar position and Class II deep-bite, no-overjet malocclusions. American Journal of Orthodontics and Dentofacial Orthopedics 96: $428-432$

Herren P 1980 Das Wirkungsprinzip des Distalbissaktivators Fortschritte der Kieferorthopaedie 41: 308-329

Ingervall B 1968 Studies of mandibular positions in children. Odontologisk Revy 19: Supplement 15

Ingervall B, Bitsanis E 1986 Function of masticatory muscles during the initial phase of activator treatment. European Journal of Orthodontics 8: 172-184

Ingervall B, Carlsson G E 1982 Masticatory muscle actinty before and after elimination of balancing side occlusal interference. Journal of Oral Rehabilitation 9: 183-192

Ingervall B, Egermark-Eriksson I 1979 Function of temporal and masseter muscles in individuals with dual bite. Angle Orthodontist 49: $131-140$

Ingervall B, Thilander B 1974 Relation between facial morphology and activity of the masticatory muscles. Journal of Oral Rehabilitation 1: 131-147

Ingervall B, Thüer U 1991 Temporal muscle activity during the first year of Class I1, division 1 malocclusion treatment with an activator American Journal of Orthodontics and Dentofacial Orthopedics 99: 361-368

Ingervall B, Ridell A, Thilander B 1979 Changes in activity of the temporal, masseter and lip muscles after surgical correction of mandibular prognathism. International Journal of Oral Surgery 8: 290-300

Möller E, Sheikholeslam A, Lous I 1984 Response of elevator activity during mastication to treatment of functional disorders. Scandinavian Journal of Dental Research 92: 64-83

Petit H P, Chateau M 1984 The K-test and the condylar test. Journal of Clinical Orthodontics 18: 726-732

Riise C, Sheikholeslam A 1984 Influence of experimental interfering occlusal contacts on the activity of the anterior temporal and masseter muscles during mastication. Journal of Oral Rehabilitation 11: 325-333

Swann G C 1954 The diagnosis and interception of Class II, division 2 malocclusion. American Journal of Orthodontics 40: $325-340$

Thūer U, Ingervall B, Būrgin W 1989 Does the mandible alter its functional position during activator treatment? American Joumal of Orthodontics and Dentofacial Orthopedics 96: 477-484 